\title{
Folk prescription for treating rhinitis as a rare cause of childhood lead poisoning: a case series
}

\author{
Xiao-Lan Ying ${ }^{1}$, Morri Markowitz ${ }^{2}$ and Chong-Huai Yan ${ }^{1 *}$
}

\begin{abstract}
Background: Folk prescriptions continue to be important sources of childhood lead poisoning. Nasal spray folk prescriptions for treating rhinitis has only been reported once previously as a cause of lead poisoning.

Case presentation: We identified three pediatric cases of severe lead poisoning caused by nasal spray folk medicines prescribed for treating rhinitis. The three patients had similar clinical manifestations including: severe abdominal pain, headache, pale appearance and fatigue. Liver function tests were abnormal. Blood lead levels (BLLs) of the three patients were $91 \mu \mathrm{g} / \mathrm{dL}, 91 \mu \mathrm{g} / \mathrm{dL}$, and $105 \mu \mathrm{g} / \mathrm{dL}$, respectively. After chelation BLLs decreased. The lead content of the three folk remedies as measured by inductively coupled plasma mass spectrometry (ICP-MS) were 14.8, 22.3, and 33.4\%. All the symptoms resolved during a course of chelation therapy. There were no severe side effects of treatment.

Conclusions: Nasal spray folk prescriptions for treating rhinitis may contain extremely high bio-accessible lead content and are potential sources of lead poisoning. Clinicians should be alert to this possibility especially in those children presenting with multisystem symptoms.
\end{abstract}

Keywords: Child, Lead poisoning, Folk medicine, Nasal spray, Rhinitis

\section{Background}

Eliminating pediatric lead poisoning remains a worldwide challenge $[1,2]$. Since symptoms of lead poisoning are nonspecific, such as abdominal pain, pale appearance, behavioral changes, headaches, fatigue, and irritability [3], the possibility of lead poisoning is easily overlooked. Thus the correct diagnosis can be delayed resulting in progression of toxicity.

The accurate identification of at-risk populations from unusual sources of lead exposure is essential to prevent further toxicity. Some cases of lead poisoning caused by folk medicines have been reported in recent years [4-6]. However, to our knowledge, only one case of lead poisoning due to a nasal spray folk remedy has been reported [7].

\footnotetext{
*Correspondence: yanchonghuai@xinhuamed.com.cn; yanch@shkeylabceh.org

${ }^{1}$ MOE-Shanghai Key Laboratory of Children's Environmental Health, Xinhua Hospital affiliated to Shanghai Jiaotong University School of Medicine, Shanghai 200092, China

Full list of author information is available at the end of the article
}

Extremely elevated BLLs (BLLs $\geq 70 \mu \mathrm{g} / \mathrm{dL}$ ) now occur rarely in children [8]. We report three cases of severe childhood lead poisoning from folk medications specifically prescribed for treating rhinitis. These cases were complicated by concurrent abnormal liver function which can affect lead poisoning treatment.

\section{Case presentation \\ Case 1}

A 7-year-old boy was referred to our hospital for an elevated $\mathrm{BLL}(>60 \mu \mathrm{g} / \mathrm{dL})$ discovered during routine screening procedures. On admission, a recheck of the BLL, tested by Atomic Absorption Spectrometry (AAS), showed the level to be $91 \mu \mathrm{g} / \mathrm{dL}$. Thus the diagnosis of lead poisoning was confirmed.

Two months before admission, he started to feel dizzy and developed headaches. Symptoms progressed to poor appetite, mouth-bitterness, repeated vomiting and abdominal pain for more than a month. The abdominal pain was intermittent, without an obvious precipitant and generally lasted for $10 \mathrm{~min}$ with spontaneous 
resolution. Subsequently, intense joint pain and fatigue occurred causing him to be unable to walk by himself.

Before admission, he had been hospitalized twice elsewhere. At his first presentation 2 months earlier, laboratory examinations found elevated serum liver enzymes: alanine transaminase (ALT) $145 \mathrm{U} / \mathrm{L}$ and aspartate aminotransferase (AST) $78 \mathrm{U} / \mathrm{L}$. He also had anemia with a hemoglobin $(\mathrm{Hb})$ level of $96 \mathrm{~g} / \mathrm{L}$ and red blood cell $(\mathrm{RBC})$ count of $3.67 \times 10^{12} / \mathrm{L}$ ). Superficial gastritis and bile reflux were found by endoscopy. An upper abdominal CT angiography showed "a general decrease in liver density; possible superior mesenteric artery syndrome". A descriptive diagnosis of "chronic superficial gastritis, possible superior mesenteric artery syndrome, and abnormal liver function tests" was made. He was treated with omeprazole and sucralfate for 2 weeks which was accompanied by relief of his symptoms. He was discharged from the hospital without an identified etiology.

Ten days after discharge, he was admitted to another hospital for intermittent vomiting and severe abdominal pain. Liver function tests, electroencephalogram and abdominal ultrasonography were normal. An incidental BLL test was performed (this hospital tests lead routinely) and reported as elevated. He was referred to our hospital for further evaluation and treatment.

On admission to our hospital, his examination found a soft, non-tender abdomen without rebound tenderness. Both liver and spleen were impalpable. Neurologic examination was normal. Abnormally increased pigmentation of the gums ("lead line") was observed (Fig. 1). No radiopaque point masses were identified on anteroposterior abdominal radiography. Anteroposterior radiograph of the knees (Fig. 2) showed increased linear radio-density at the distal femoral and proximal tibial and fibular metaphyses. Serum chemistries were normal. The $\mathrm{RBC}$ count was $3.68 \times 10^{12} / \mathrm{L}$ (reference range 4.0 $5.5 \times 10^{12} / \mathrm{L}$ ) and the $\mathrm{Hb}$ level was $101 \mathrm{~g} / \mathrm{L}$ (reference range 120-150 g/L), consistent with anemia.

A more detailed history about sources of lead exposure was taken. He had been using a red-colored folk medicine

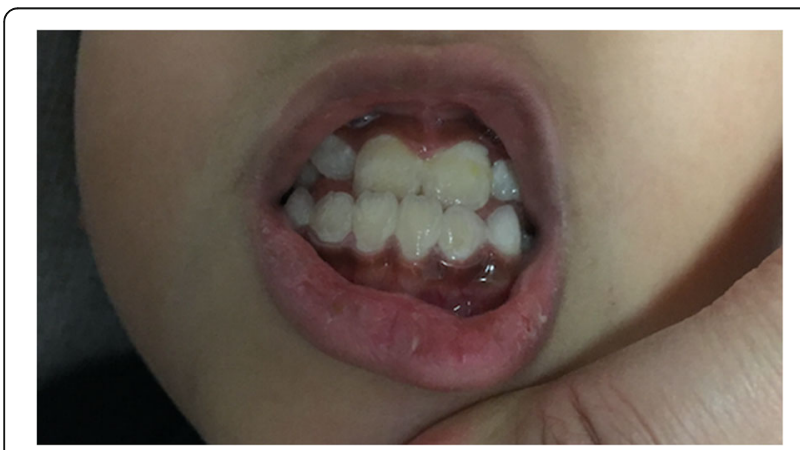

Fig. 1 Gum lead line
(Fig. 3), spraying it in the nostrils two to four times a day during the week prior to consulting a doctor. The nasal spray liquid was obtained from a traditional Chinese medicine (TCM) practitioner (Shenzhen, Guangdong, China). Analysis of the liquid revealed a lead concentration of $148,000 \mathrm{mg} / \mathrm{kg}$ (14.8\%) as measured by ICP-MS.

Chelation therapy combined orally administered dimercaptosuccinic acid (DMSA) $\left(350 \mathrm{mg} / \mathrm{m}^{2}\right.$ body surface area, $\mathrm{q} 8 \mathrm{~h}$ ) and intravenous calcium disodium edetate $\left(\mathrm{CaNa}_{2} \mathrm{EDTA}\right)\left(1 \mathrm{~g} / \mathrm{m}^{2}\right.$ body surface area, continuous infusion using a micro-pump over $24 \mathrm{~h}$ ) for 5 days. Glutathione $(600 \mathrm{mg}$, intravenous drip, once a day) was added as an antioxidant. All the symptoms resolved; and the BLL declined to $21 \mu \mathrm{g} / \mathrm{dL}$ after chelation therapy was completed.

\section{Case 2}

An 8-year-old girl with rhinitis had consulted the same TCM practitioner as in case 1 and was prescribed the same nasal spray liquid to be used twice a day for 10 days. She developed severe abdominal colic, vomiting, constipation and felt fatigued. Her venous BLL was $91 \mu \mathrm{g} / \mathrm{dL}$. The nasal spray contained 223,000 $\mathrm{mg} / \mathrm{kg}$ (22.3\%) lead. Abnormal laboratory test results included: creatine kinase $747 \mathrm{U} / \mathrm{L}$ (reference range 30-135 U/L), creatine kinase isoenzyme $\mathrm{MB} 14.8 \mathrm{ng} / \mathrm{mL}$ (reference range 0-6.8 ng/mL); AST $119 \mathrm{U} / \mathrm{L}$ (reference range 8$38 \mathrm{U} / \mathrm{L}$ ), ALT $390 \mathrm{U} / \mathrm{L}$ (reference range 0-75 U/L). Radiography of the abdomen revealed shadow of stool and gas as well as points of increased density (Fig. 4).

It could not be determined whether the radiopaque particles seen on the abdominal $\mathrm{x}$-ray contained lead or not. Since chelating agents may increase gut lead absorption, folium sennae was administered as a cathartic to eliminate lead from the intestine prior to initiating chelation. The chelation regimen was identical with case 1. However, after 2 days of therapy the white blood cell count fell to $2.11 \times 10^{9} / \mathrm{L}$ (normal range: $4.0-10.0 \times 10^{9} /$ L). This may be attributed to DMSA, which was withheld subsequently. Chelation continued with an intravenous infusion of $\mathrm{CaNa}_{2} \mathrm{EDTA}$ to achieve a BLL of $36 \mu \mathrm{g} / \mathrm{dL}$ at the end of 5 days.

\section{Case 3}

A 5-year-old boy had consulted the same TCM practitioner as in Cases 1 and 2 and was prescribed the same medication to be used twice a day for 7 days. Severe abdominal pain and vomiting followed. Prior to transfer to our hospital his initial laboratory data showed markedly elevated liver enzyme levels (ALT $1083 \mathrm{U} / \mathrm{L}$, AST $972 \mathrm{U} / \mathrm{L})$. No abnormality was found on abdominal $\mathrm{x}$-ray. On examination, his liver was palpable $4 \mathrm{~cm}$ below the right costal margin. The BLL on admission was $105 \mu \mathrm{g} / \mathrm{dL}$. The nasal spray contained 33.4\% lead. 


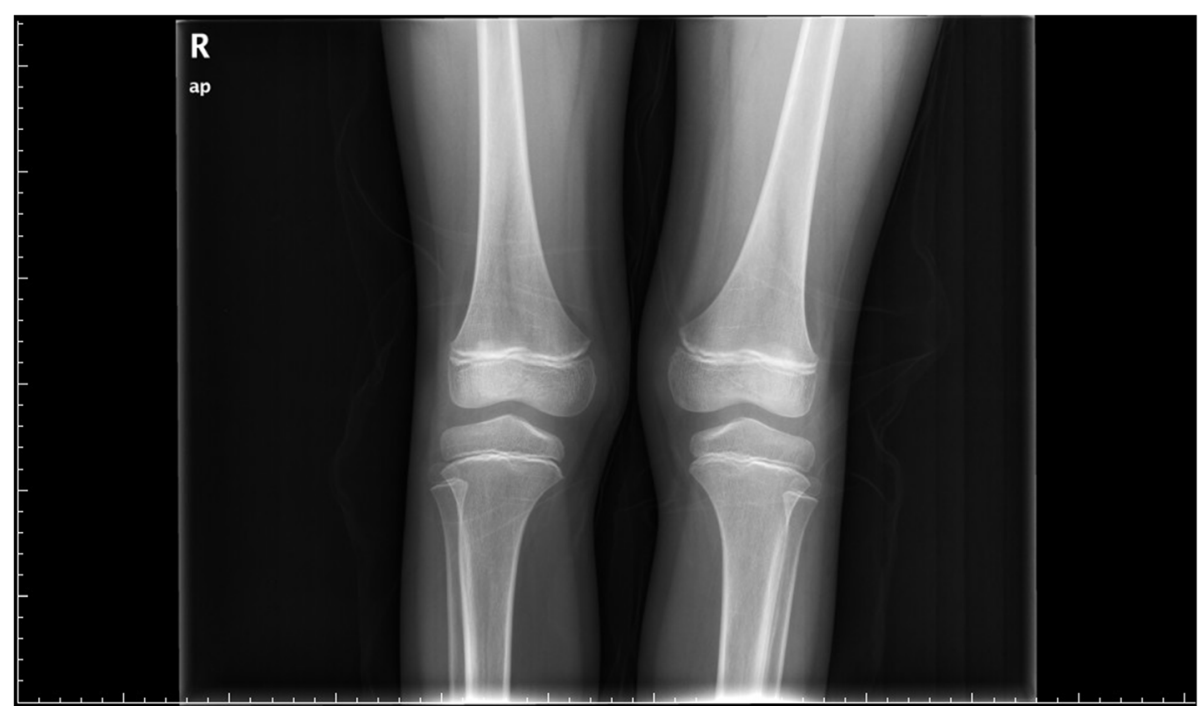

Fig. 2 Anteroposterior radiograph of the knees bilaterally

Chelation therapy was initially withheld because of the severely altered liver enzyme results as both drugs are potentially hepatotoxic. Initially, he received treatment aimed at improving liver function with glutathione and disodium glycyrrhetate (Table 1) and continued to receive these medications during the whole course of treatment. As his liver function tests improved, his BLL went down concomitantly, prior to chelation (Table 1, BLL of Day 1: $105 \mu \mathrm{g}$ /dL; Day 4: $96 \mu \mathrm{g} / \mathrm{dL}$; Day 8: $80 \mu \mathrm{g} / \mathrm{dL}$ ) at which point chelation treatment was initiated with DMSA and $\mathrm{CaNa}_{2}$ EDTA infusion (same usage as Case 1). The post-chelation lead level for this child was $34 \mu \mathrm{g} / \mathrm{dL}$. No adverse events happened to all the three children.

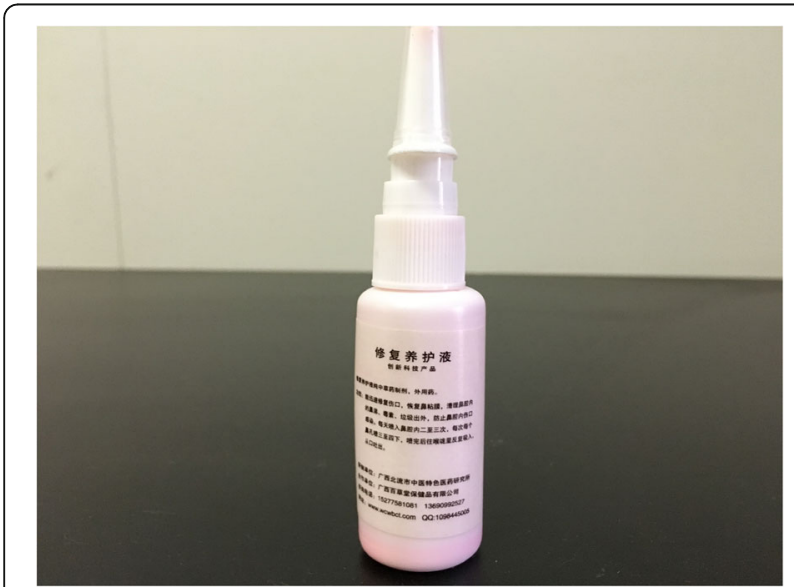

Fig. 3 Folk medicine for treating rhinitis

\section{Discussion}

\section{Absorption of lead}

Ingestion and inhalation are the two primary modes of lead entry into the body. The former is more common in children due to hand-to-mouth activity, while the latter occurs more frequently in occupationally exposed adults [9]. The percentage of lead absorbed from the gut depends on factors as follows: particle size, gastric $\mathrm{pH}$,

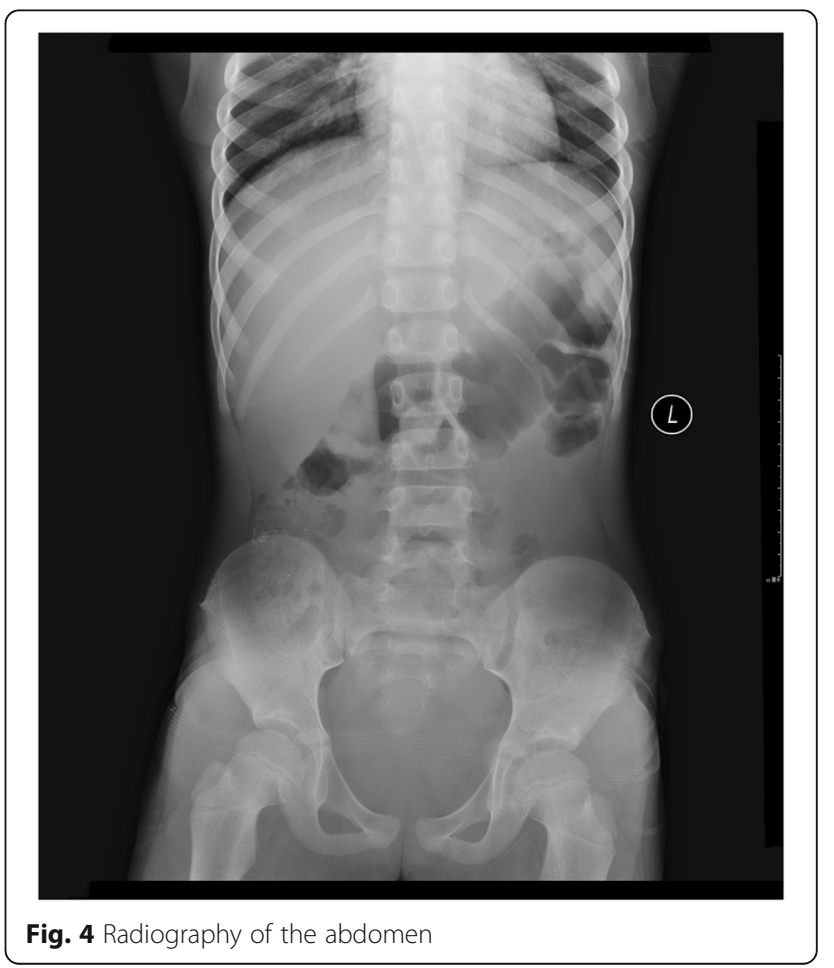


Table 1 Liver function test during therapy

\begin{tabular}{|c|c|c|c|c|c|c|c|c|c|c|c|c|}
\hline Variable & Reference range & Day $1^{a}$ & Day 2 & Day 3 & Day 4 & Day 5 & Day 6 & Day 7 & Day $8^{b}$ & Day9 & Day 10 & Day 13 \\
\hline ALT (U/L) & $0-75$ & 641 & 521 & 415 & 317 & 254 & 197 & 176 & 117 & 124 & 14 & 67 \\
\hline AST (U/L) & $8-38$ & 280 & 137 & 102 & 91 & 85 & 75 & 81 & 57 & 93 & 23 & 40 \\
\hline
\end{tabular}

${ }^{a}$ Day 1: Start to get liver-protecting treatment in our hospital

${ }^{b}$ Day 8: Start chelation therapy combined with liver-protecting treatment

other material in the gut, and nutritional status of essential elements [10]. Inhalational absorption through the lung depends on particle size.

The three patients had reportedly short-term exposures to nasal spray liquids for treating rhinitis that had extremely high lead concentrations. The short period of exposure is consistent with acute lead poisoning. This folk remedy was sprayed directly into the nostrils. All three children mentioned that they tasted and swallowed the liquid. Thus, the lead was potentially absorbed from multiple sites including the nasal mucosa, the lungs, as well as the gastrointestinal tract.

\section{Diagnosis of lead poisoning}

Abdominal pain caused by lead poisoning has been reported $[11,12]$. Possibly the delay in diagnosis in our patients was due to a lack of awareness by the physicians of its features in children. This highlights the need to educate clinicians including subspecialists about this disease. Lead poisoning should be in the list of possible diagnoses for children with unexplained multi-systems symptoms, especially of the gastrointestinal and central nervous systems.

These children also had detectable signs of lead poisoning. The line of gingival hyperpigmentation [13] in the first patient has been described in occupationally lead exposed adults [14]. He also had a "lead line" on long bone radiography. The width of the dense metaphysis has been reported to correlate with the length of the period of toxic exposure [15].

\section{Folk remedy as a potential source of lead poisoning}

Lead poisoning can be diagnosed through the determination of the lead concentration in whole blood. In children, an elevated BLL indicates the need to identify the sources of exposure that likely lead to ingestion. While typical environmental sources predominate as the cause of lead poisoning, cultural factors are also important. Besides lead-containing paint, various sources of lead were identified for children with $\mathrm{BLL} \geq 45 \mu \mathrm{g} / \mathrm{dL}$ in New York City: imported spices, cosmetics, as well as traditional folk medicines [8]. A detailed history about the usage of traditional folk medicine is essential. Laboratory analyses of these medicines will then determine the lead content.

Lead poisoning due to folk remedies for treating skin problems [16], abdominal pain [17], epilepsy [18], or "strengthening eyes" [19] have been reported before. However, a nasal spray folk remedy for treating rhinitis as a potential source of lead poisoning has only been reported in a single adult [7]. As shown in Fig. 3 the container can look completely ordinary for a nasal spray and is clearly not an indicator of safety. Usage of such products in children should prompt clinicians to consider lead screening and public health agencies to educate local communities of the risks of their use.

Historically, the compositions of folk medicines were proprietary and medicine containers did not indicate the constituents. Given the high concentrations that we found it's likely that the Traditional Chinese Healer purposefully added lead to the nasal spray, presumably because he felt it offered a therapeutic benefit. Given the known and potentially lethal toxicity of lead, its medicinal use should be prohibited. These cases highlight the need for governmental oversight of folk medicine content.

\section{Treatment of lead intoxication}

Despite intestinal and neurological symptoms the diagnosis of lead poisoning was delayed. Hepatotoxicity was observed in our patients as evidenced by elevated transaminase levels. Both DMSA and $\mathrm{CaNa}_{2}$ EDTA can be hepatotoxic; pretreatment evaluation of liver function is necessary. With DMSA, a transient mild rise of hepatic transaminases is the most common adverse effect reported, generally resolving on discontinuation of treatment without long-term sequelae. Published studies on the frequency of this transaminase increase differ, varying between $<1.5$ and $60 \%$ of patients [20,21]. In a multicenter placebo controlled DMSA trial conducted in children with initial BLLs between 20 and $45 \mu \mathrm{g} / \mathrm{dL}$, no difference in the rate of elevated ALT levels in treated versus untreated children was observed [22].

Although hepatic damage is not a common feature of childhood lead poisoning [23, 24], animal studies have found that chronic lead poisoning caused mild histological and histochemical changes in the liver [25]. The very high liver enzyme levels in case 3 delayed chelation. With the conservative approach taken, liver function recovered quickly and BLLs declined. Spontaneous excretion of lead in patients with acute lead poisoning may have a greater impact on BLLs than those with more chronic lead poisoning since lead has not had time to accumulate in bone. 


\section{Conclusions}

Although the differential diagnosis of lead poisoning is broad, any child who presents with unexplained GI and CNS symptoms should undergo a BLL test, which will directly support or reject the diagnosis of lead toxicity.

Folk remedies for treating rhinitis can be an unexpected source of lead exposure. It is incumbent on pediatricians to perform a diligent search for unconventional sources of lead when confronted with cases without an apparent etiology.

\section{Abbreviations}

AAS: Atomic absorption spectroscopy; ALT: Alanine transaminase; AST: Aspartate Aminotransferas; BLLs: Blood lead levels; $\mathrm{CaNa}_{2} \mathrm{EDTA}$ : Calcium disodium edetate; DMSA: Dimercaptosuccinic acid; Hb: Hemoglobin; ICP-MS: Inductively coupled plasma mass spectrometry; RBC: Red blood cells; TCM: Traditional Chinese medicine

\section{Acknowledgements}

This work was supported by the grant from the National Basic Research Program of China (Technology 973 Program, Grant No. 2012CB525001).

\section{Funding}

This work was supported by the National Basic Research Program of China (Technology 973 Program, Grant No. 2012CB525001) in the collection, analysis, and interpretation of data and in writing the manuscript.

\section{Availability of data and materials}

All data generated or analysed during this study are included in this published article.

\section{Authors' contributions}

$X Y$ collected the materials of the case, carried out the initial analyses, drafted the initial manuscript, and approved the final manuscript as submitted. MM reviewed and revised the manuscript, and approved the final manuscript as submitted. CY designed the data collection instruments, and coordinated and supervised data collection, critically reviewed the manuscript, and approved the final manuscript as submitted. All authors approved the final manuscript as submitted and agree to be accountable for all aspects of the work.

\section{Ethics approval and consent to participate}

This case study was approved by the Research Ethics Board of Xinhua Hospital. Parental consent was obtained for participants under 16.

\section{Consent for publication}

Written informed consents were obtained from the parents of the patients for publication of this case series and any accompanying images. A copy of the written consents are available for review by the Editor of this journal.

\section{Competing interests}

The authors declare that they have no competing interests.

\section{Publisher's Note}

Springer Nature remains neutral with regard to jurisdictional claims in published maps and institutional affiliations.

\section{Author details}

${ }^{1}$ MOE-Shanghai Key Laboratory of Children's Environmental Health, Xinhua Hospital affiliated to Shanghai Jiaotong University School of Medicine, Shanghai 200092, China. 'Division of Environmental Sciences, Children's Hospital at Montefiore, Albert Einstein College of Medicine, Bronx NY10467, USA.
Received: 6 July 2017 Accepted: 25 June 2018

Published online: 06 July 2018

\section{References}

1. McClure LF, Niles JK, Kaufman HW. Blood lead levels in young children: US, 2009-2015. J Pediatr. 2016;175:173-81.

2. Falk H. International environmental health for the pediatrician: case study of lead poisoning. Pediatrics. 2003;112(1 Pt 2):259-64.

3. Woolf AD, Goldman R, Bellinger DC. Update on the clinical management of childhood lead poisoning. Pediatr Clin North Am. 2007;54(2):271-94. viii

4. Breeher L, Mikulski MA, Czeczok T, et al. A cluster of lead poisoning among consumers of Ayurvedic medicine. Int J Occup Environ Health. 2015;21(4):303-7.

5. $\quad$ in $C G$, Schaider $L A$, Brabander DJ, et al. Pediatric lead exposure from imported Indian spices and cultural powders. Pediatrics. 2010;125(4):e828-35.

6. Woolf AD, Hussain J, McCullough L, et al. Infantile lead poisoning from an Asian tongue powder: a case report \& subsequent public health inquiry. Clin Toxicol (Phila). 2008;46(9):841-4.

7. Lan F, Lin J, Chen MX. [A case of nonindustrial lead poisoning caused by the nasal spray folk prescription](in Chinese). Strait J Prev Med. 2014 20(06):93-4.

8. Keller B, Faciano A, Tsega A, et al. Epidemiologic characteristics of children with blood lead levels >/=45 mug/dL. J Pediatr. 2017;180:229-34.

9. Dapul H, Laraque D. Lead poisoning in children. Adv Pediatr Infect Dis. 2014;61(1):313-33

10. Markowitz M. Lead poisoning. In: Kliegman RM, editor. Nelson textbook of pediatrics [M]. 19th Elsevier Saunders; 2011. p. 2448-53.

11. Shamshirsaz AA, Yankowitz J, Rijhsinghani A, et al. Severe lead poisoning caused by use of health supplements presenting as acute abdominal pain during pregnancy. Obstet Gynecol. 2009;114(2 Pt 2):448-50.

12. Frith $D$, Yeung $K$, Thrush $S$, et al. Lead poisoning-a differential diagnosis for abdominal pain. Lancet. 2005;366(9503):2146.

13. Pearce JM. Burton's line in lead poisoning. Eur Neurol. 2007;57(2):118-9.

14. Nogue S, Culla A. Images in clinical medicine. Burton's line. N Engl J Med. 2006:354(20):e21.

15. Chandrasekar S, Lomasney LM, Derhammer N. Systemic lead toxicity. Orthopedics. 2015:38(10):592. 644-597

16. Mathee A, Naicker N, Teare J. Retrospective investigation of a lead poisoning outbreak from the consumption of an Ayurvedic medicine: Durban, South Africa. Int J Environ Res Public Health. 2015;12(7):7804-13.

17. Cabb EE, Gorospe EC, Rothweiler AM, et al. Toxic remedy: a case of a 3-yearold child with lead colic treated with lead monoxide (greta). Clin Pediatr (Phila). 2008;47(1):77-9.

18. Ying $\mathrm{XL}, \mathrm{Xu}$ J, Markowitz $\mathrm{M}$, et al. Pediatric lead poisoning from folk prescription for treating epilepsy. Clin Chim Acta. 2016;461:130-4.

19. Jones TF, Moore WL, Craig AS, et al. Hidden threats: lead poisoning from unusual sources. Pediatrics. 1999;104(5 Pt 2):1223-5.

20. Bradberry S, Vale A. Dimercaptosuccinic acid (succimer; DMSA) in inorganic lead poisoning. Clin Toxicol (Phila). 2009;47(7):617-31.

21. Thurtle N, Greig J, Cooney L, et al. Description of 3,180 courses of chelation with dimercaptosuccinic acid in children $\leq 5 \mathrm{y}$ with severe lead poisoning in Zamfara, northern Nigeria: a retrospective analysis of programme data. PLoS Med. 2014;11(10):e1001739.

22. Rogan WJ, Bornschein RL, Chisolm JJ, et al. Safety and efficacy of succimer in toddlers with blood lead levels of 20-44 $\mu \mathrm{g} / \mathrm{dL}$. Pediatr Res. 2000;48(5):593-9.

23. Verheij J, Voortman J, van Nieuwkerk CM, et al. Hepatic morphopathologic findings of lead poisoning in a drug addict: a case report. J Gastrointestin Liver Dis. 2009;18(2):225-7.

24. Beattie AD, Mullin PJ, Baxter RH, et al. Acute lead poisoning: an unusual cause of hepatitis. Scott Med J. 1979;24(4):318-21.

25. Jarrar BM, Taib NT. Histological and histochemical alterations in the liver induced by lead chronic toxicity. Saudi J Biol Sci. 2012;19(2):203-10. 